OPEN ACCESS

Edited by:

Tae-Hee Cho,

Hospices Civils de Lyon, France

Reviewed by:

Christian H. Nolte,

Charité Universitätsmedizin Berlin,

Germany

Noreen Kamal,

University of Calgary, Canada

*Correspondence:

Jean Marc Olivot

jmolivot@gmail.com

Specialty section: This article was submitted to

Stroke,

a section of the journal

Frontiers in Neurology

Received: 08 August 2018 Accepted: 09 October 2018

Published: 26 October 2018

Citation:

Raposo N, Albucher JF, Rousseau V,

Acket B, Chollet $F$ and Olivot JM

(2018) ED Referral Dramatically Reduces Delays of Initial Evaluation in a French TIA Clinic

Front. Neurol. 9:914.

doi: 10.3389/fneur.2018.00914

\section{ED Referral Dramatically Reduces Delays of Initial Evaluation in a French TIA Clinic}

\author{
Nicolas Raposo ${ }^{1,2,3}$, Jean François Albucher ${ }^{1,2,3}$, Vanessa Rousseau ${ }^{3}$, Blandine Acket ${ }^{1,2}$, \\ François Chollet ${ }^{1,2}$ and Jean Marc Olivot ${ }^{1,2,3 *}$ \\ ${ }^{1}$ Department of Neurology, Toulouse University Medical Center, Toulouse, France, ${ }^{2}$ Toulouse University Neuro Imaging \\ Center, UMR 1214, Toulouse, France, ${ }^{3}$ Toulouse University Medical Center, Clinical Investigation Center, Toulouse, France
}

Background: The risk of recurrent brain infarction (BI) is high within the first hours after a transient ischemic attack (TIA). Emergent, specialized, and tailored patient management in a TIA program reduces the risk of recurrent BI after TIA by $80 \%$. New antithrombotic strategies have been successfully tested within $12 \mathrm{~h}$ after TIA onset. We aim to investigate the factors associated with a delay of more than $12 \mathrm{~h}$ from TIA onset to evaluation in our TIA clinic.

Methods: In consecutive patients evaluated in our TIA clinic from 01/2012 to $11 / 2013$, we prospectively collected delays from onset to arrival, baseline characteristics, discharge diagnosis and recurrent $\mathrm{BI}$ at 1 week. Referring pathways were dichotomized between office-based physicians (OBP) and emergency departments (ED). Univariate and multivariate logistic regression were performed.

Results: 354 patients were evaluated. Mean (+/- SD) age was 61 years $(+/-18)$. Median (IQR) ABCD2 score was 3 (2-4). Median (IQR) delay from onset to evaluation was $8 \mathrm{~h}$ (4-48). Overall, 185 (52\%) were referred by OBP vs. 169 (48\%) by ED. Evaluation was initiated within $12 \mathrm{~h}$ among 201 (57\%) patients. After logistic regression, OBP referral was by comparison with $\mathrm{ED}$ the only independent factor associated with an evaluation delay $>12$ h (OR 5.7, 95\% Cl: 3.5-9.3, p < 0.0001).

Conclusion: Our results suggest that preliminary assessment by OBP may increase the delay to initiate the emergent evaluation of TIA patients. Promoting direct admission to TIA clinics through ED may be an efficient alternative for high risk TIAs.

Keywords: transient ischemic attack, TIA clinic, triage, referral, office-based physician, emergency department, delay of care

\section{INTRODUCTION}

Up to one third of cases of acute brain infarction (BI) have been preceded by a transient ischemic attack (TIA) (1). The early risk of BI is high after TIA. The risk of invalidating BI after a TIA is major during the first hours following the event (2-4). The emergent, specialized, and tailored management of TIA in the setting of a specific TIA pathway (TIA clinic, clinical decision unit; etc.) reduces the risk of recurrent stroke by $80 \%(5,6)$. Recently, the Platelet-Oriented Inhibition in New TIA (POINT) study demonstrated that the combination of aspirin with clopidogrel therapy initiated within $12 \mathrm{~h}$ after TIA onset reduces the risk of recurrent BI by comparison with aspirin alone (7). Therefore, delays in TIA patient evaluation may have a major impact on the risk of recurrent stroke after a TIA. 
The emergent management of TIA patients is challenging because the public awareness of the signs of TIA is limited, (8) and the agreement on the clinical diagnosis of the ischemic mechanism of transient neurological symptoms, even by stroke specialist physicians, is low (9).

Two types of medical referral can be distinguished:(10). The first type is Office Based Physician (OBP) referral: The first TIA clinics created in Paris and Oxford were dedicated to accommodating primary care physicians (PCP) to refer TIA patients via a toll free number $(5,6)$. Hence in Oxfordshire, up to $80 \%$ of the patients referred to a TIA clinic did seek medical attention through their PCP first (11). As a consequence, OBP availability (12) as well as their awareness of the risk of stroke after a TIA, (13) could critically influence the delay in patient management. The second type is an Emergency department (ED) referral: in this pathway, patients experiencing TIA symptoms come directly to ED or through a call to the French national medical emergency telephone number (15, equivalent to 911 in the USA). TIA patients are initially evaluated by ER physicians, and then managed by the local stroke team in a clinical decision unit, (14) in a stroke department or referred, after undergoing a predefined work up, to an outpatient TIA program (Two ACES Model) (14-16).

Interestingly, although factors associated with a shorter delay in the management of patients with acute stroke have been identified $(17,18)$, little is known about the impact of the type of medical referral to a TIA program by OBP vs. ED, or about the delay in initiating emergent comprehensive evaluation of TIA patients.

In 2012, we created a TIA clinic in our stroke unit able to accommodate OBP as well as ED referrals using a toll-free number following the SOS-TIA model (5). Following the same approach we used to monitor IV thrombolysis, during the first 2 years, we collected data on the delays from symptom onset to the initiation of the evaluation by our TIA clinic.

With this as background, we investigated the factors associated with the delay between the symptom onset and the initiation of the evaluation in our TIA clinic using $12 \mathrm{~h}$ as a cut off for evaluation.

\section{METHODS}

\section{Patients}

Clinical information on consecutive patients referred to our TIA clinic between January, 2012 and November, 2013, were prospectively collected and reviewed. Patients with suspected TIA were referred through a toll free number to our outpatient TIA clinic. The ABCD2 score was dichotomized between $<4$ (low risk) and $\geq 4$ (moderate to high risk). Final diagnosis and orientation (hospitalization vs. discharge) and rate of recurrent $\mathrm{BI}$ at 1 week were also prospectively recorded. Referral was dichotomized into 2 categories: OBP and ED.

\section{TIA Clinic}

Our TIA clinic is composed of 2 monitored beds inside the stroke unit functioning during business hours. At night and during weekends, patients were initially evaluated in the ER then eventually transferred to the unit. When they arrived at the TIA clinic, patients are immediately evaluated by a senior stroke neurologist and underwent, when indicated, emergent MRI, vessel imaging, and expedited complementary work up. Patients were admitted to our stroke unit if they fulfilled admission criteria such as positive DWI lesion on MRI, symptomatic vessel stenosis, recurrent TIA, atrial fibrillation or per the attending stroke neurologist's judgment.

\section{Statistical Analysis}

For descriptive analyses, continuous variables are expressed as means and standard deviations (SD) or medians and interquartile ranges (IQR), and categorical variables are expressed as frequencies and percentages. Baseline characteristics were compared according to physician referral type. Factors associated with a delay from symptom onset to admission were compared using multivariate logistic regression model. The delay is categorized into two groups: $>12$ and $\leq 12 \mathrm{~h}$. Hence, the model estimated the probability of having a delay of medical care of more than $12 \mathrm{~h}$ depending on patient characteristics before admission to the TIA clinic. The potential associated factors were: gender (M (ref) vs. F), physician referral (OBP vs. ED), hypertension (yes/no), diabetes (yes/no), dyslipidemia (yes/no), current smoker (yes/no), atrial fibrillation (yes/no), previous stroke or TIA (yes/no), number of TIA episodes (single (ref) vs. recurrent), and ABCD2 score ( $<4$ vs. $\geq 4$ (19)). For the binary factors, the modality "no" was already the reference class. The multivariate model was obtained by including significant associated factors at $30 \%$ in univariate models and performing step by step backward elimination. No adjustment was made, i.e., the final model contains only significant factors.

Statistical tests were 2-tailed and were conducted at an alpha level of 5\%. Data were analyzed using SAS ${ }^{\circledR}$ software, version 9.4 (SAS Institute).

The study was approved by our hospital research and ethics committee.

\section{RESULTS}

From January 2012 to November 2013, 354 consecutive patients were evaluated by our TIA program. Baseline characteristics are presented on Table 1. Median (IQR) ABCD2 score was 3 (24 ), and $135(38.1 \%)$ had an ABCD2 $\geq 4$. Half of the patients (185, $52 \%)$ were referred by an OBP: $129(70 \%)$ by PCP, 2 (1\%) by cardiologists, 23 (12\%) by ophthalmologists, $31(17 \%)$ others, and 167 (48\%) by ED. An MRI was performed on 277 patients $(78 \%)$ and cervical and intracranial vessel imaging on $306(86 \%)$. An acute DWI lesion was detected in 53 (19\%) of these patients, and a symptomatic stenosis in $16(5 \%)$ patients. The final discharge diagnosis from the attending stroke neurologist was TIA or minor stroke in 208 (59\%) patients and non-ischemic event in $146(41 \%)$ patients. At the end of evaluation $25 \%$ of the patients were admitted to the stroke unit.

By comparison with patients referred by $\mathrm{ED}$, patients referred by OBP tended to have an ABCD2 score <4 (68 vs. $56 \%$, Chi2 Test: $p=0.02$ ). 
TABLE 1 | Clinical and Radiological characteristics of the patients.

\begin{tabular}{|c|c|c|c|c|}
\hline & Overall $N=354$ & Evaluation initiated within $12 \mathrm{~h} \mathrm{~N}=201$ & Evaluation beyond $12 \mathrm{~h} \mathrm{~N}=153$ & $P$-value \\
\hline Age Mean $(+/-S D)$ & $61.2 \pm 17.9$ & $60.1 \pm 18.6$ & $62.5 \pm 16.9$ & $0.28^{x}$ \\
\hline Female, $n(\%)$ & $176(49.7 \%)$ & 95 (47.3\%) & 81 (52.9\%) & 0.29 \\
\hline ABCD2, Median (IQR) & $3(2-4)$ & $3(2-4)$ & $3(2-4)$ & $0.06^{x}$ \\
\hline $\mathrm{ABCD} 2 \geq 4, n(\%)$ & $135(38.1 \%)$ & 87 (43.3\%) & 48 (31.4\%) & 0.02 \\
\hline Delay from onset to evaluation, Median (IQR) & $8(4-48)$ & $4(2-6)$ & $48(24-96)$ & \\
\hline \multicolumn{5}{|l|}{ Referral type } \\
\hline Office Based Physician n (\%) & $185(52.3 \%)$ & $73(36.3 \%)$ & $112(72.2 \%)$ & $<0.0001$ \\
\hline Emergency Medical Services, $n(\%)$ & 169 (47.7\%) & $128(63.7 \%)$ & $41(26.8 \%)$ & \\
\hline Number of TIA episodes (>1), $n(\%)$ & $60(17.8)^{+}$ & $27(14.1 \%)$ & $33(22.6 \%)$ & 0.04 \\
\hline Hypertension $n(\%)$ & $144(40.7 \%)$ & $79(39.3 \%)$ & $65(42.5 \%)$ & 0.55 \\
\hline Diabetes, $n(\%)$ & 34 (9.6\%) & $17(8.5 \%)$ & 17 (11.1\%) & 0.40 \\
\hline Hypercholesterolemia, $n$ (\%) & $109(31.3 \%)^{\star}$ & $57(28.9 \%)$ & $52(34.4 \%)$ & 0.27 \\
\hline History of stroke or TIA, $n$ (\%) & $55(15.8 \%)^{\star}$ & $33(16.8 \%)$ & $22(14.6 \%)$ & 0.58 \\
\hline History of Ml, $n$ (\%) & $21(6.0 \%)^{\star}$ & $10(5.1 \%)$ & $11(7.3 \%)$ & 0.39 \\
\hline Atrial fibrillation, $n(\%)$ & $15(4.2 \%)$ & $9(4.5 \%)$ & $6(3.9 \%)$ & 0.80 \\
\hline MRI performed, $n$ (\%) & 277 (78.3\%) & $159(79.1 \%)$ & $118(77.1 \%)$ & 0.65 \\
\hline Positive DWI lesion, $n$ (\%) & $53(19.1 \%)^{\circ}$ & $33(20.8 \%)$ & 20 (16.9\%) & 0.43 \\
\hline Cervical \& intracranial vessel imaging, $n(\%)$ & $306(86.4 \%)$ & $176(87.6 \%)$ & $130(85.0 \%)$ & 0.48 \\
\hline Symptomatic stenosis/occlusion, $n$ (\%) & $16(5.2 \%)^{\$}$ & $13(7.4 \%)$ & $3(2.3 \%)$ & 0.05 \\
\hline Discharge Diagnosis, TIA or minor stroke, $n(\%)$ & $208(58.8 \%)$ & $117(58.2 \%)$ & $91(59.5 \%)$ & 0.81 \\
\hline Recurrent stroke at 1 week & $3(0.9 \%)$ & $3(1.5 \%)$ & $0(0.0 \%)$ & $0.26^{\#}$ \\
\hline
\end{tabular}

*6 (1.7\%) missing data: 4 (2.0\%) in $12 h$ and 2 (1.3\%) after $12 h$.

${ }^{\circ}$ Among patients with MRI performed.

$\$$ Among patients with Cervical \& intracranial vessel imaging.

${ }^{x}$ Wilcoxon Test.

\#Fisher Test.

+16 (4.5\%) missing data: 9 (4.5\%) in $12 h$ and 7 (4.6\%) after $12 h$.

Median (IQR) delay from onset to arrival in TIA clinic was $8 \mathrm{~h}$ (4-48). Initial evaluation was initiated within $12 \mathrm{~h}$ after symptom onset in 201 patients (57\%). Figure 1 shows the distribution of this delay.

Univariate analysis showed that OBP referral $(p<0.0001)$, number of TIA episodes $(p=0.04)$ and ABCD2 score $<4(p=$ 0.04 ) were associated with a delay between onset to evaluation $>12 \mathrm{~h}$. After multivariate analysis, referral type (ED vs. OBP) was the only factor associated with the delay from onset to arrival (OR 5.7, 95\% CI [3.5-9.3]; $p=0.0001)$.

In the subgroup of $286(81 \%)$ patients evaluated $\leq 48 \mathrm{~h}$ after TIA, only OBP referral was associated with a delay $>12 \mathrm{~h}(\mathrm{OR}$ 10.7, 95\% CI [5.0-26.5]; $p<0.0001)$.

\section{DISCUSSION}

Our results suggest that in our TIA program, the type of initial medical referral to a TIA clinic critically influences the delay of the initial evaluation.

Baseline characteristics of the patients referred to our TIA program, e.g., median $\mathrm{ABCD} 2$ score, DWI positive results, rate of symptomatic vessel stenosis, were in keeping with the results observed in other datasets. By the end of their evaluation, 25\% of patients were admitted to the stroke unit. Finally, the rate of recurrent stroke at 1 week was $1.8 \%$. Altogether, those results are in keeping with the findings of the TIA registry published in 2016 (2).
Our results show that in our region, OBP remains the most common type of patient referral. Two thirds of referring OBP were general practitioners. Typically, OBP had limited access to the resources required for the emergent comprehensive evaluation of TIA patients. Therefore, TIA clinic programs were initially designed 15 years ago to expedite the evaluation of these patients $(5,6)$. Conversely, almost half of the patients were referred by ED. Two thirds of them were referred by the ED of our hospital. These patients were typically directly triaged to our TIA clinic by the triage nurse upon arrival in our ED.

Interestingly, recurrent TIA was more frequent in the subgroup of patients evaluated $>12 \mathrm{~h}$ after onset. In line with previous studies, these findings suggest that patient awareness of the signs of TIAs does play an important role in delay $(11,20)$. This relationship did not persist in multivariate analysis. However, this finding suggests that patient awareness of TIA symptoms does play a critical role in delays for initial evaluation. Unfortunately, in the absence of a regional registry, we do not know how many patients did experience a brain infarction after being evaluated in our TIA clinic. In addition, our program, and other similar programs, do evaluate patients who have experienced TIA symptoms within the past few days. We hypothesize that such patients were more prone to visit their PCP rather than contacting ED. In order to address this bias, we restricted our analyses to the subgroup of patients who were initially evaluated by OBP and ED within $48 \mathrm{~h}$ after TIA, and again, OBP referral was the only independent factor 


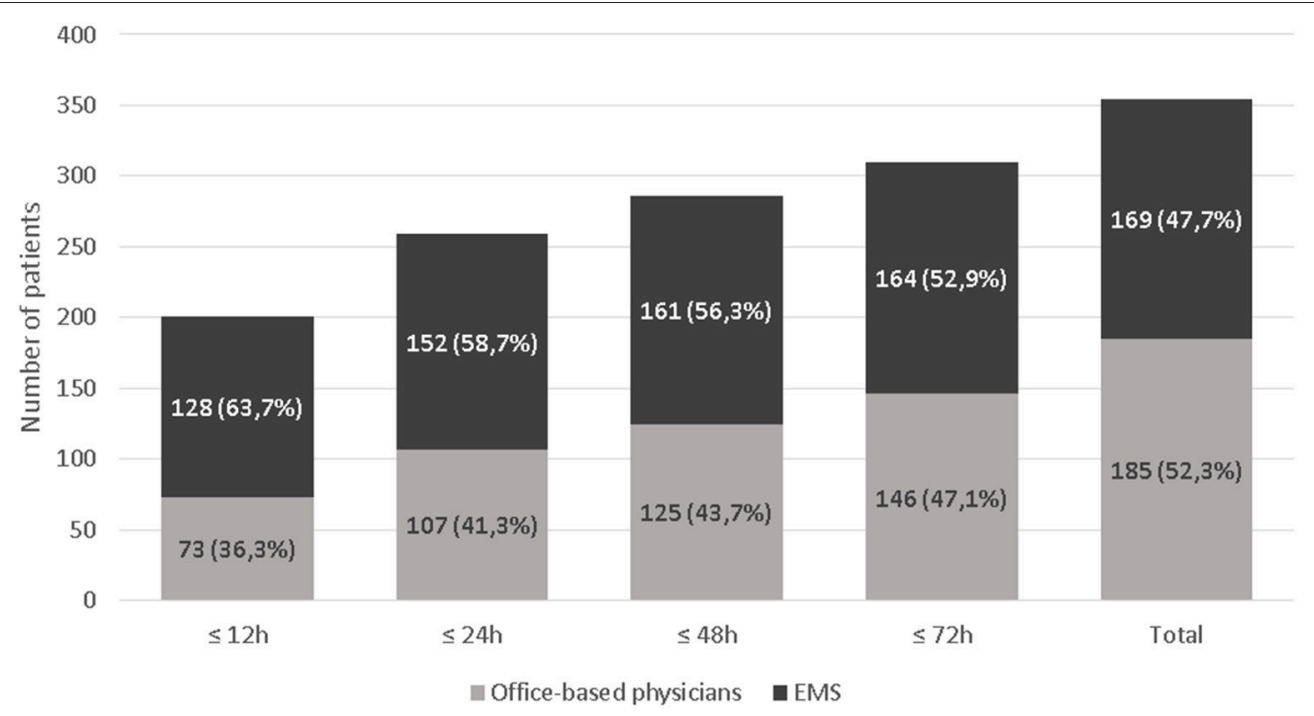

FIGURE 1 | Proportion of patients evaluated within 12, 24, 48, and $72 \mathrm{~h}$ according to the type of medical referral.

associated with a delay $>12 \mathrm{~h}$ for initiating evaluation in the TIA clinic.

Recently, intensive prevention strategies have shown promising results (SOCRATES trial, (21) POINT trial (7)) or are currently (Thales trial; ClinicalTrials.gov: NCT03354429) tested within the first hours after high risk TIA/minor stroke onset defined by simple criteria: such as transient/recurrent/persistent speech disturbance and/or arm weakness in patients with high risk condition (atrial fibrillation, vessel stenosis). Our results suggest that triaging such patients by ED may increase the rate of patients who will receive such emergent treatment within the recommended time window. Interestingly, in our dataset patients referred by ED were more likely to have some of those characteristics such as an ABCD2 score $>4$ suggesting that some of them may be easily implemented for the triage of such patients. However, several studies have shown that a significant proportion of patients with low ABCD2 score and/or unusual TIA symptoms are still at a high risk of recurrent $\mathrm{BI}$ and should therefore be rapidly evaluated in a TIA clinic (22). ABCD2 score accuracy for predicting the risk of stroke after a TIA has been shown to be limited compared to DWI lesion or vascular stenosis or occlusion (4, 23-26).

Our study suffers from several limitations. First the retrospective data collection from a single TIA clinic, and the absence of systematic TIA and stroke registry in our region, create a selection bias and only reflects the characteristics of the patients that were eventually evaluated though our TIA program. Second, our dataset was collected 4 years ago, and since then our program has merged with another similar TIA program, which is currently being, remodeled to incorporate the evolution of TIA management and enrollment into randomized trials. Information campaign and national and European recommendations are currently written to incorporate new aspects of TIA management discussed above.
A new evaluation from larger datasets such as the TIA registry, including other types of TIA programs in other countries, is essential.

The creation of a specific TIA program has been a breakthrough for stroke prevention in the past decade. The initiation of new specific strategies for high risk TIA/minor stroke is now one of the next major challenges for acute phase stroke management. Early identification of high risk TIA/minor stroke patient by ED and transfer to a dedicated structure appears to be an essential step in facing this challenge. Even when they are referred by ED, a number of patients with TIA symptoms experience delays in the management in the TIA clinic, suggesting that information campaigns to the general public on the symptoms of TIA and the early risk of stroke after a TIA are urgently needed.

\section{CONCLUSION}

In the era of expedited pathways for the evaluation and management of TIA patients, triage by ED results in more expeditious evaluation compatible with emergent therapeutic strategies currently tested to prevent brain infarction after TIA/minor stroke.

\section{ETHICS STATEMENT}

Our manuscript has been reviewed and approved by our local Clinical Research Comitee.

\section{AUTHOR CONTRIBUTIONS}

NR, JA, FC, BA, and JO acquired data. NR and JO conceived the study. JO drafted the manuscript. VR performed the statistical analysis. NR, JA, FC, and VR reviewed the manuscript. 


\section{REFERENCES}

1. Rothwell PM, Warlow CP. Timing of TIAs preceding stroke: time window for prevention is very short. Neurology (2005) 64:817-20. doi: 10.1212/01.WNL.0000152985.32732.EE

2. Amarenco P, Lavallee PC, Labreuche J, Albers GW, Bornstein NM, Canhao P, et al. One-year risk of stroke after transient ischemic attack or minor stroke. N Engl J Med. (2016) 374:1533-42. doi: 10.1056/NEJMoa1412981

3. Chandratheva A, Mehta Z, Geraghty OC, Marquardt L, Rothwell PM. Oxford Vascular S. Population-based study of risk and predictors of stroke in the first few hours after a TIA. Neurology (2009) 72:1941-7. doi: 10.1212/WNL.0b013e3181a826ad

4. Hill MD, Yiannakoulias $\mathrm{N}$, Jeerakathil $\mathrm{T}$, Tu JV, Svenson LW, Schopflocher DP. The high risk of stroke immediately after transient ischemic attack: a population-based study. Neurology (2004) 62:2015-20. doi: 10.1212/01.WNL.0000129482.70315.2F

5. Lavallee PC, Meseguer E, Abboud H, Cabrejo L, Olivot JM, Simon $\mathrm{O}$, et al. A transient ischaemic attack clinic with round-the-clock access (SOS-TIA): feasibility and effects. Lancet Neurol. (2007) 6:953-60. doi: 10.1016/S1474-4422(07)70248-X

6. Rothwell PM, Giles MF, Chandratheva A, Marquardt L, Geraghty O, Redgrave JN, et al. Effect of urgent treatment of transient ischaemic attack and minor stroke on early recurrent stroke (EXPRESS study): a prospective population-based sequential comparison. Lancet (2007) 370:1432-42. doi: 10.1016/S0140-6736(07)61448-2

7. Johnston SC, Easton JD, Farrant M, Barsan W, Conwit RA, Elm JJ, et al. Clopidogrel and aspirin in acute ischemic stroke and high-risk TIA. N Engl J Med. (2018) 379:215-225. doi: 10.1056/NEJMoa1800410

8. Toole JF. Transient ischemic attack: awareness and prevalence in the community. Health Rep. (1994) 6:121-5.

9. Castle J, Mlynash M, Lee K, Caulfield AF, Wolford C, Kemp S, et al. Agreement regarding diagnosis of transient ischemic attack fairly low among stroke-trained neurologists. Stroke (2010) 41:1367-70. doi: 10.1161/STROKEAHA.109.577650

10. Evans BA, Ali K, Bulger J, Ford GA, Jones M, Moore C, et al. Referral pathways for patients with TIA avoiding hospital admission: a scoping review. BMJ Open (2017) 7:e013443. doi: 10.1136/bmjopen-2016-013443

11. Chandratheva A, Lasserson DS, Geraghty OC, Rothwell PM. Oxford Vascular S. Population-based study of behavior immediately after transient ischemic attack and minor stroke in 1000 consecutive patients: lessons for public education. Stroke (2010) 41:1108-14. doi: 10.1161/STROKEAHA.109. 576611

12. Lasserson DS, Chandratheva A, Giles MF, Mant D, Rothwell PM. Influence of general practice opening hours on delay in seeking medical attention after transient ischaemic attack (TIA) and minor stroke: prospective population based study. BMJ (2008) 337:a1569. doi: 10.1136/bmj.a1569

13. Streit S, Baumann P, Barth J, Mattle HP, Arnold M, Bassetti CL, et al. Awareness of stroke risk after TIA in Swiss general practitioners and hospital physicians. PLoS ONE (2015) 10:e0135885. doi: 10.1371/journal.pone. 0135885

14. Vora N, Tung CE, Mlynash M, Garcia M, Kemp S, Kleinman J, et al. TIA triage in emergency department using acute MRI (TIA-TEAM): a feasibility and safety study. Int J Stroke (2015) 10:343-7. doi: 10.1111/ijs. 12390

15. Bravata DM, Myers LJ, Arling G, Miech EJ, Damush T, Sico JJ, et al. Quality of care for veterans with transient ischemic attack and minor stroke. JAMA Neurol. (2018) 75:419-27. doi: 10.1001/jamaneurol.2017.4648
16. Olivot JM, Wolford C, Castle J, Mlynash M, Schwartz NE, Lansberg MG, et al. Two aces: transient ischemic attack work-up as outpatient assessment of clinical evaluation and safety. Stroke (2011) 42:1839-43. doi: 10.1161/STROKEAHA.110.608380

17. Rossnagel K, Jungehulsing GJ, Nolte CH, Muller-Nordhorn J, Roll S, Wegscheider K, et al. Out-of-hospital delays in patients with acute stroke. Ann Emerg Med. (2004) 44:476-83. doi: 10.1016/j.annemergmed.2004.06.019

18. Bouckaert M, Lemmens R, Thijs V. Reducing prehospital delay in acute stroke. Nat Rev Neurol. (2009) 5:477-83. doi: 10.1038/nrneurol.2009.116

19. Johnston SC, Rothwell PM, Nguyen-Huynh MN, Giles MF, Elkins JS, Bernstein AL, et al. Validation and refinement of scores to predict very early stroke risk after transient ischaemic attack. Lancet (2007) 369:283-92. doi: 10.1016/S0140-6736(07)60150-0

20. Stroebele N, Muller-Riemenschneider F, Nolte CH, Muller-Nordhorn J, Bockelbrink A, Willich SN. Knowledge of risk factors, and warning signs of stroke: a systematic review from a gender perspective. Int J Stroke (2011) 6:60-6. doi: 10.1111/j.1747-4949.2010.00540.x

21. Johnston SC, Amarenco P. Ticagrelor versus aspirin in acute stroke or transient ischemic attack. N Engl J Med. (2016) 375:1395. doi: 10.1056/NEJMoa1603060

22. Amarenco P, Labreuche J, Lavallee PC, Meseguer E, Cabrejo L, Slaoui $\mathrm{T}$, et al. Does $\mathrm{ABCD} 2$ score below 4 allow more time to evaluate patients with a transient ischemic attack? Stroke (2009) 40:3091-5. doi: 10.1161/STROKEAHA.109.552042

23. Perry JJ, Sharma M, Sivilotti ML, Sutherland J, Symington C, Worster A, et al. Prospective validation of the ABCD2 score for patients in the emergency department with transient ischemic attack. CMAJ (2011) 183:1137-45. doi: $10.1503 / \mathrm{cmaj} .101668$

24. Kamal N, Hill MD, Blacquiere DP, Boulanger JM, Boyle K, Buck B, et al. Rapid assessment and treatment of transient ischemic attacks and minor stroke in canadian emergency departments: time for a paradigm shift. Stroke (2015) 46:2987-90. doi: 10.1161/STROKEAHA.115.010454

25. Calvet D, Touze E, Oppenheim C, Turc G, Meder JF, Mas JL. DWI lesions and TIA etiology improve the prediction of stroke after TIA. Stroke (2009) 40:187-92. doi: 10.1161/STROKEAHA.108.515817

26. Coutts SB, Simon JE, Eliasziw M, Sohn CH, Hill MD, Barber PA,et al. Triaging transient ischemic attack and minor stroke patients using acute magnetic resonance imaging. Ann Neurol. (2005) 57:848-54. doi: 10.1002/ana.20497

Conflict of Interest Statement: JA received consulting fees from Bayer and speaker honoraria from Boehringer Ingelheim, Bayer and Pfizer. FC served as a consultant for Institut de Recherche Pierre Fabre and has received speaker honoraria from Bristol-Myers Squibb and Boston Scientific. JO received consulting fees from AstraZeneca, Servier, and Medtronic and speaker honoraria from Pfizer and Bristol Myers Squibb.

The remaining authors declare that the research was conducted in the absence of any commercial or financial relationships that could be construed as a potential conflict of interest.

Copyright (C) 2018 Raposo, Albucher, Rousseau, Acket, Chollet and Olivot. This is an open-access article distributed under the terms of the Creative Commons Attribution License (CC BY). The use, distribution or reproduction in other forums is permitted, provided the original author(s) and the copyright owner(s) are credited and that the original publication in this journal is cited, in accordance with accepted academic practice. No use, distribution or reproduction is permitted which does not comply with these terms. 